\title{
Platelet Function Tests and Inflammatory Markers for the Differentiation of Primary Thrombocytosis and Secondary Thrombocytosis
}

\author{
Piyapong Kanya ${ }^{1}$, Ekarat Rattarittamrong ${ }^{2 *}$, Ornkamon Wongtagan ${ }^{2}$, Thanawat \\ Rattanathammethee $^{2}$, Chatree Chai-Adisaksopha ${ }^{2}$, Adisak Tantiworawit ${ }^{2}$, Lalita \\ Norasetthada $^{2}$
}

\begin{abstract}
Background: The prognosis and management of primary thrombocytosis (PT) and secondary thrombocytosis (ST) are different. This study aims to evaluate the role of platelet function tests by light transmission platelet aggregometry (LTA), plasma von Willebrand factor antigen (vWF:Ag), ristocetin cofactor activity (vWF:RCo) and inflammatory markers [erythrocyte sedimentation rate (ESR), C-reactive protein (CRP)] for the differentiation between PT and ST. Methods: This prospective study was carried out in patients with platelet counts greater than $450 \times 10^{9} / \mathrm{L}$. Primary outcomes were the sensitivity and specificity of platelet function tests by LTA for the differentiation of PT and ST. Secondary outcomes were sensitivity and specificity of ESR, CRP, vWF:Ag, and vWF:RCo for the differentiation of PT and ST. Results: Fifty-two patients were enrolled onto the study of which $26(50 \%)$ had PT. The sensitivity and specificity of epinephrine, collagen, and arachidonic acid (AA) induced abnormal LTA for the differentiation of PT from ST were sensitivity of $50 \%, 38.5 \%, 26.9 \%$ and specificity of $88.5 \%, 100 \%, 100 \%$ respectively. The sensitivity and specificity of abnormal ESR, CRP, and either abnormal ESR or CRP in the differentiation of ST from PT were sensitivity of $88.5 \%, 80.8 \%, 100 \%$ and specificity of $65.4 \%, 61.5 \%, 46.2 \%$ respectively. The sensitivity and specificity of low vWF:Ag and vWF:RCo in the differentiation of PT from ST were sensitivity of 7.69\%, 42.3\% and specificity of $100 \%, 88.5 \%$ respectively. Conclusions: Abnormal platelet function determined by LTA with collagen, AA, epinephrine had high specificity ratings enabling the differentiation between PT and ST. vWF:RCo, ESR and CRP levels could be helpful in differentiating between PT and ST.
\end{abstract}

Keywords: Light transmission platelet aggregometry- erythrocyte sedimentation rate- C-reactive protein

Asian Pac J Cancer Prev, 20 (7), 2079-2085

\section{Introduction}

Thrombocytosis is defined as the presence of a high platelet count,specifically more than the upper limit of normal or more than $450 \times 10^{9} / \mathrm{L}$. This condition can be classified as primary thrombocytosis (PT) resulting from a clonal bone marrow abnormality such as myeloproliferative neoplasm (MPN), reactive or secondary thrombocytosis (ST) and inherited thrombocytosis(Rodgers et al., 2014; Beer et al., 2011).

The most common form of thrombocytosis is ST. The most common cause of PT is essential thrombocythemia (ET) (Schafer, 2004; Rose et al., 2012). ET, polycythemia vera(PV), primary myelofibrosis(PMF), and chronic myeloid leukemia (CML) are MPNs characterized by clonal proliferation of hematopoietic stem cells. Platelets in these disorders show not only quantitative but also qualitative changes by switching from resting to pro-coagulant phenotypes (Barbui et al., 2013). In addition, a decrease in the number of largevon Willebrand factor (vWF) multimers has been noted in patients with MPN, and this decline correlates with an increased platelet count (Tiede et al., 2011; Kumaret al., 2002).

The natural history of a MPN is marked by thrombohemorrhagic complications and a propensity for the transformation to myelofibrosis and acute leukemia (Carobbio, et al., 2011). In contrast, ST is usually considered as a reactive process without thrombohemorrhagic issues, but its underlying causes must be identified and treated (Schafer, 2004).

The mechanisms of an increase number of platelets in ST are unclear. In many cases, ST is driven by elevated endogenous levels of interleukin (IL) - 6, other cytokines, or catecholamines that may accompany inflammatory, 
infectious, malignant or stress linked situations (Schafer, 2001). Many markers of the acute phase reactants including C-reactive protein (CRP) and erythrocyte sedimentation rate (ESR) are also significantly elevated in patients with reactive as opposed to clonal thrombocytosis (Bleeker and Hogan, 2011; Bashir et al., 2014; Tefferi et al., 1994).

Platelet function is generally analyzed using a platelet function analyzer (PFA)-100 and light transmission platelet aggregometry (LTA). LTA measures the ability of various agonists to induce in vitro platelet activation (Harrison, 2005). In a previous study into platelet function tests in thrombocytosis, abnormal results are suggestive of ET while normal outcomes from both investigations can be used to exclude ET (Tsantes et al., 2010).

Since data is limited regarding surrogate markers to differentiate PT from ST, the aim of this study was to evaluate the role of platelet functiontests by LTA, plasma vWFantigen (vWF:Ag), ristocetin cofactor activity (vWF:RCo) and inflammatory markers (ESR, CRP)to enable differentiation between PT and ST.

\section{Materials and Methods}

\section{Study overview}

This was a prospective study enrolling patients aged18 years or older who had platelet counts of more than $450 \times 10^{9} / \mathrm{L}$ and were admitted to or attended the out-patient clinic at Chiang Mai University Hospital, Thailand from November 2016 to December 2017. They were categorized as PT based on the revised 2016 World Health Organization criteria (Arber et al., 2016) and ST. All patients in PT group had to have been confirmed by a positive Philadelphia chromosome (for diagnosis of CML), JAK2V617F or calreticulin (CALR) gene mutation (for diagnosis of PV, ET, or PMF). The patients with ST had to have been diagnosed with underlying diseases which can cause thrombocytosis. Exclusion criteria were patients had been given chemotherapy agents or a tyrosine kinase inhibitor within four weeks prior to evaluation and/ or received antiplatelet or non-steroidal anti-inflammatory drugs within 14 days prior to evaluation, or had chronic kidney disease with a decreased glomerular filtration rate less than $60 \mathrm{ml} / \mathrm{min} / 1.73 \mathrm{~m}^{2}$ for more than three months. Written informed consent was obtained from all patients.

Blood samples were obtained sent for LTA, ESR, CRP, vWF:Ag, and vWF:RCo analysis. Controlled blood samples for LTA were obtained from volunteers. The agonists in the platelet function test by LTA (Chrono-Log Aggregometer Model 700, United States) were high dose adenosine diphosphate (ADP) 10 micromolar $(\mu \mathrm{M})$, epinephrine (Epi) $10 \mu \mathrm{M}$, high dose ristocetin $1 \mathrm{mg} / \mathrm{mL}$, arachidonic acid (AA)1 millimolar (mM)and collagen $2 \mu \mathrm{M}$. Abnormal LTA was defined as platelet aggregation less than $60 \%$ at five minutes after adding the agonists.

Whole blood samples anti-coagulated with EDTA were used to determine ESR level based on red blood cell aggregation method (Ves-Matic Cube 30, Italy). The CRP level was tested using monoclonal antibodies specific to human CRP, aggregated when mixed with plasma containing CRP (BN ProSpec system, United
States). Abnormal ESR and CRP were defined as values greater than the upper limit of normal $(>10 \mathrm{~mm} / \mathrm{hr}$ and $>5 \mathrm{mg} / \mathrm{L}$ respectively). The level of $\mathrm{vWF}: \mathrm{Ag}$ was measured by an automated latex enhanced immunoassay (ACL TOP 500, United States). The vWF:RCo was tested by measuring the ability of a vWF in the plasma which causes an agglutination of the ristocetin and stabilizes platelets contained in the von Willebrand reagent (Sysmex CS-2500, Japan). Low vWF:Ag and vWF:RCo was defined as a value less than the lower limits of normal (vWF:Ag< $42 \%$ in blood group $\mathrm{O}$ and $<66 \%$ in other blood groups; vWF:RCo $<70 \%$ ). Clinical characteristics and thrombohemorrhagic complications were assessed from the patients and medical records.

\section{Outcomes}

Primary outcomes were the sensitivity $(\mathrm{Se})$ and specificity ( $\mathrm{Sp}$ ) of platelet function tests by LTA enabling the differentiation between PT and ST. Secondary outcomes were Se and Sp of ESR, CRP, vWF:Ag, and vWF:RCo for the differentiation of PT and ST as well as correlations between these markers and thrombohemorrhagic complications in patients with PT and ST.

\section{Statistical Analysis}

Descriptive statistics were presented as a mean with corresponding standard deviation (SD), a median with range, or percentages.Categorical variables were compared using the Chi-squared test or Fisher exact test as appropriate. Continuous variables were compared using a student t-test or Wilcoxon rank-sum test (Mann-Whitney test) as appropriate. The platelet function tests and inflammatory markers for the differentiation of ST and PT were presented as Se, Sp, positive predictive value (PPV), and negative predictive value (NPV). The factors associated with thrombohemorrhagic complications were presented as odds ratio (OR) and 95\% confidence interval (CI). Level of statistical significance was defined as $p$-value $<0.05$. For a power of $95 \%$ and $\alpha$ error of 0.05 to detect differentiation of primary outcome between groups, abnormal results of platelet function test were estimated at $80 \%$ in cases of PT and $30 \%$ in ST (Tsantes et al., 2010). The total number of patients needed for enrollment was calculated to be 46 . Analyses were performed using the Statistical Package for Social Sciences, version 22.0.

\section{Results}

\section{Clinical Characteristics of Patients}

Fifty-two patients with a median age of 49.5 (range, 18 - 89) years were included in the study. Twenty-three patients $(44.2 \%)$ were male. There was no significant difference in age and sex between groups. Twenty-six patients $(50 \%)$ had PT including $14(53.8 \%) \mathrm{CML}$, nine (34.6\%) JAK2 V617F mutated ET, one (3.9\%) CALR mutated ET, one (3.9\%) JAK2V617F mutated PMF, and one (3.9\%) JAK2V617F mutated PV. Twenty-six patients $(50 \%)$ had ST including ten $(38.5 \%)$ malignancies, eight (30.8\%) chronic infections, five (19.2\%) post-splenectomy 
Table 1. Clinical Characteristics of Patients with Primary and Secondary Thrombocytosis

\begin{tabular}{lcccc}
\hline Parameters & $\begin{array}{c}\text { Total }(\mathrm{N}=52) \\
\text { mean } \pm \mathrm{SD}\end{array}$ & $\begin{array}{c}\mathrm{PT}(\mathrm{N}=26) \\
\text { mean } \pm \mathrm{SD}\end{array}$ & $\begin{array}{c}\mathrm{ST}(\mathrm{N}=26) \\
\text { mean } \pm \mathrm{SD}\end{array}$ & P-value \\
\hline Age $($ years $)$ & $51.1 \pm 18.2$ & $52.6 \pm 19.6$ & $49.5 \pm 16.9$ & 0.547 \\
$\mathrm{Hb}(\mathrm{g} / \mathrm{dl})$, & $9.9 \pm 2.3$ & $10.4 \pm 2.8$ & $9.5 \pm 1.6$ & 0.163 \\
$\mathrm{WBC}(\mathrm{x} \mathrm{10} / \mathrm{L})$, & 16 & 61 & 13.1 & $<0.001$ \\
Platelet count $\left(\mathrm{x} 10^{9} / \mathrm{L}\right)$, & $928.6 \pm 491.9$ & $1,149.5 \pm 593.2$ & $707.6 \pm 200.9$ & $<0.001$ \\
\hline
\end{tabular}

$\mathrm{Hb}$, hemoglobin; WBC, white blood cell; SD, standard deviation; PT, primary thrombocytosis; ST, secondary thrombocytosis; JAK2, Janus Kinase 2; CALR, calreticulin; SD, standard deviation; min, minimum; max, maximum.

states, and three $(11.5 \%)$ autoimmune diseases. In this group, twenty-one patients $(80.8 \%)$ had a normal platelet count when followed up in the outpatient clinic. The rest of the patients that had a persistent thrombocytosis were secondary from post-splenectomy. Seven patients (26.9\%) in the ST group also underwent JAK2 V617F testing, all tested negative.

No significant difference was noted in the mean hemoglobin $(\mathrm{Hb})$ level between groups. The median white blood cell (WBC) count was greater in the PT patients compared with ST $\left(61 \times 10^{9} / \mathrm{L}\right.$ vs. $13.1 \times 10^{9} / \mathrm{L}$, $\mathrm{p}<0.001)$. The mean platelet count was also greater in PT patients compared with ST $\left(1,149.5 \times 10^{9} / \mathrm{L}\right.$ vs. 707.6 $\left.\mathrm{x} 10^{9} / \mathrm{L}, \mathrm{p}<0.001\right)$. According to the clinical presentation reports, fever was more common in the ST patients compared with PT $(57.7 \%$ vs. $11.5 \%, \mathrm{p}<0.001)$. In contrast, splenomegaly was more common in cases of PT compared with ST $(69.2 \%$ vs. 7.7\%, p < 0.001) (Table 1 and 2). In the ST group, all patients with splenomegaly were diagnosed with lymphoma.

Comparison of frequency of parameters such as platelet function tests using light transmission platelet aggregometry, inflammatory markers, von Willebrand factor antigens, ristocetinco factor activity and thrombohemorrhagic complications between primary and secondary thrombocytosis is shown in Table 3.

\section{Platelet Function Tests in Primary and Secondary} Thrombocytosis

The median platelet aggregation in response to Epi was significantly decreased in the PT patients compared with those with ST $(60 \%$ vs. $74.5 \%, p=0.012)$ while there was no significant difference observed in response to ADP, collagen, ristocetin and AA (Table 4). The proportion of the patients with abnormal LTA induced by Epi, collagen and AA were significant higher in PT patients compared with ST.

\section{Inflammatory Markers in Primary and Secondary} Thrombocytosis

Median ESR $(8.4 \mathrm{~mm} / \mathrm{hr}$ vs. $57 \mathrm{~mm} / \mathrm{hr}, \mathrm{p}<0.001)$ and CRP (3.8 mg/L vs. $27.1 \mathrm{mg} / \mathrm{L}, \mathrm{p}<0.01)$ were significantly lower in PT patients compared with ST (Table 4). The proportion of patients with high abnormal ESR and CRP levels were significantly lower in PT patients compared with ST. There was a significant higher proportion of patients in ST group who has abnormal levels of both ESR and CRP as compared to PT group.

\section{vWF:Ag and vWF:RCo in Primary and Secondary Thrombocytosis}

Mean vWF:Ag (150.8\% vs. 210\%, p =0.015) and vWF:RCo $(90.5 \%$ vs. $148.3 \%, \mathrm{p}<0.001)$ were significantly lower in PT patients compared with ST (Table 2). No significant difference in proportion of patients with low vWF:Ag was shown between groups whereas the PT group had a significantly greater proportion of patients with low vWF:RCo.

Thrombohemorrhagic Complications in Primary and Secondary Thrombocytosis

Thrombohemorrhagic complications at the time of diagnosis were found in six (23.1\%)patients in PT[three $(11.5 \%)$ with ischemic stroke, one (3.9\%) limb ischemia, one $(3.9 \%)$ bleeding of ruptured corpus luteum, and one (3.9\%)had intra-operative bleeding], while none of these occurred in ST patients $(\mathrm{p}=0.009)$. All cases of arterial thrombosis (four patients; $15.4 \%$ ) were JAK2 V617F mutated ET whereas all hemorrhagic complications (two patients; 7.7\%) occurred in cases of CML (Table 3). All of bleeding patients had low vWF:RCo.

\section{Primary and Secondary Outcomes}

The Se, Sp, PPV and NPV of abnormal LTA induced by Epi, collagen, AA and Epi plus at least one agonist of collagen and AA in the differentiation of PT from ST are

Table 2. Clinical Characteristic Frequency of Patients with Primary and Secondary Thrombocytosis

\begin{tabular}{lcccc}
\hline & Total $\mathrm{N}=52(100 \%)$ & $\mathrm{PT} \mathrm{N}=26(100 \%)$ & $\mathrm{ST} \mathrm{N}=26(100 \%)$ & P-value \\
\hline Male & $23(44.2)$ & $12(46.2)$ & $11(42.3)$ & 0.78 \\
Anemic Symptom & $3(5.8)$ & $1(3.8)$ & $2(7.7)$ & 1 \\
Fever & $18(34.6)$ & $3(11.5)$ & $15(57.7)$ & $<0.001$ \\
B-symptom & $18(34.6)$ & $6(23.1)$ & $12(46.2)$ & 0.08 \\
Hepatomegaly & $25(48.1)$ & $16(61.5)$ & $9(34.6)$ & 0.052 \\
Splenomegaly & $20(38.5)$ & $18(69.2)$ & $2(7.7)$ & 0.001 \\
\hline
\end{tabular}


Table 3. Comparison of Frequency of Parameters such as Platelet Function Tests Using Light Transmission Platelet Aggregometry, Inflammatory Markers, von Willebrand Factor Antigens, Ristocetin Cofactor Activity and Thrombohemorrhagic Complications between Primary and Secondary Thrombocytosis.

\begin{tabular}{|c|c|c|c|}
\hline & $\mathrm{PT}(\mathrm{n}=26)$ & $\mathrm{ST}(\mathrm{n}=26)$ & P-value \\
\hline & $\mathrm{N}(\%)$ & $\mathrm{N}(\%)$ & \\
\hline \multicolumn{4}{|l|}{ Abnormal LTA } \\
\hline ADP & $5(19.2)$ & $2(7.7)$ & 0.223 \\
\hline Epi & $13(50.0)$ & $3(11.7)$ & 0.003 \\
\hline Collagen & $10(38.5)$ & $3(11.6)$ & $<0.001$ \\
\hline Ristocetin & $7(26.9)$ & & 0.159 \\
\hline AA & $7(26.9)$ & 0 & 0.004 \\
\hline Epi and at least one: high dose ADP, collagen, high dose ristocetin, and AA & $11(42.3)$ & $2(7.7)$ & 0.004 \\
\hline \multicolumn{4}{|l|}{ Abnormal levels of inflammatory marker } \\
\hline ESR & $9(34.6)$ & $23(88.5)$ & $<0.001$ \\
\hline CRP & $10(38.5)$ & $21(80.8)$ & 0.002 \\
\hline ESR and CRP & $5(19.2)$ & $18(69.2)$ & $<0.001$ \\
\hline ESR or CRP & $14(53.9)$ & $26(100)$ & $<0.001$ \\
\hline Low vWF:Ag & $2(7.7)$ & 0 & 0.149 \\
\hline Low vWF:RCo & $11(42.3)$ & $3(11.54)$ & 0.012 \\
\hline Thrombohemorrhagic complications & $6(23.1)$ & 0 & 0.009 \\
\hline
\end{tabular}

PT, primary thrombocytosis; ST, secondary thrombocytosis; ADP, adenosine diphosphate; Epi, epinephrine; AA, arachidonic acid;ESR, erythrocyte sedimentation rate; CRP, C-reactive protein; vWF:Ag, von Willebrand factor antigen; vWF:RCo, ristocetin cofactor activity.

shown in Table 5. The sensitivity of each agonist was 50\%, $38.5 \%, 26.9 \%$ and $38.5 \%$, respectively. The specificity of Epi was $88.5 \%$ and other agonists were $100 \%$ while the PPV of Epi was $81.3 \%$ and $100 \%$ for others. The NPV of each agonist was $63.9 \%, 61.9 \%, 57.8 \%$ and $61.9 \%$, respectively.

The Se, Sp, PPV, and NPV of abnormal ESR in the differentiation of ST from PT were $88.5 \%, 65.4 \%$,

Table 4. Comparison of Median Parameters such as Platelet Function Tests Using Light Transmission Platelet Aggregometry, Inflammatory Markers, Von Willebrand Factor Antigens, Ristocetin Cofactor Activity and Thrombohemorrhagic Complications between Primary and Secondary Thrombocytosis.

\begin{tabular}{lccc}
\hline & $\begin{array}{c}\text { PT }(\mathrm{n}=26) \\
\text { median(Range) }\end{array}$ & $\begin{array}{c}\text { ST }(\mathrm{n}=26) \\
\text { median(Range) }\end{array}$ & P-Value \\
\hline LTA & & & \\
ADP & $74.5(18-100)$ & $74(35-97)$ & 0.707 \\
Epi & $60(4-100)$ & $74.5(12-93)$ & 0.012 \\
Collagen & $71(0-100)$ & $76.5(60-93)$ & 0.115 \\
Ristocetin & $80.5(9-100)$ & $82.5(16-98)$ & 0.475 \\
AA & $77(8-100)$ & $77(62-99)$ & 0.741 \\
Inflammatory markers, & & \\
ESR (mm/hr) & $8.4(1-67)$ & $57(1-79)$ & $<0.001$ \\
CRP (mg/L) & $3.8(3.1-108)$ & $27.1(3.1-194)$ & $<0.001$ \\
ESR and CRP & $5(19.2)$ & $18(69.2)$ & $<0.001$ \\
ESR or CRP & $14(53.9)$ & $26(100)$ & $<0.001$ \\
\hline
\end{tabular}

PT, primary thrombocytosis; ST, secondary thrombocytosis; LTA, light transmission platelet aggregometry; SD, standard deviation; ADP, adenosine diphosphate; Epi, epinephrine; AA, arachidonic acid;ESR, erythrocyte sedimentation rate; CRP, C-reactive protein; vWF:Ag, von Willebrand factor antigen; vWF:RCo, ristocetin cofactor activity.
$71.9 \%$ and $85 \%$ while the corresponding figures for abnormal CRP were $80.8 \%, 61.5 \%, 67.7 \%$ and $76.2 \%$, respectively. The Se, Sp, PPV, and NPV of low vWF:Ag in the differentiation of PT from ST were $7.69 \%, 100 \%$, $100 \%$ and $52 \%$ while low vWF:RCo were $42.3 \%, 88.5 \%$, $78.6 \%$ and $60.5 \%$, respectively (Table 5 ).

\section{Subgroup Analysis in Essential Thrombocythemia Patients}

The sensitivity, specificity, PPV and NPV of abnormal LTA induced by Epi, collagen, AA and Epi plus at least one agonist of collagen and AA in the differentiation of ET from ST are shown in Table 5. The Se of each agonist was $50 \%, 40 \%, 30 \%$, and $30 \%$, respectively. The specificity of Epi was $88.5 \%$ and other agonists were all 100\%. PPV of Epi was $62.5 \%$ and $100 \%$ for others. The NPV of each agonist was $82.1 \%, 81.3 \%, 78.8 \%, 78.8 \%$, respectively.

The Se, Sp, PPV and NPV of abnormal ESR in the differentiation of ST from ET were $88.5 \%, 60 \%, 85.2 \%$ and $66.7 \%$ while the corresponding figures for abnormal CRP were $80.8 \%, 60 \%, 84 \%$ and $54.5 \%$ respectively.

\section{Factors Associated with Thrombohemorrhagic Complications}

The patients with thrombohemorrhagic complications had a significantly greater mean platelet count compared with patients without these complications $\left(1,837 \times 10^{9} / \mathrm{L}\right.$ vs. $\left.810.1 \times 10^{9} / \mathrm{L}, \mathrm{p}<0.001\right)$. Abnormal LTA induced by Epi $(100 \%$ vs. $21.74 \%, \mathrm{p}<0.001)$ and collagen $(66.67 \%$ vs. $13.04 \%, p=0.009)$ presented significantly in patients with thrombohemorrhagic complications. No significant difference in the levels of ESR, CRP, vWF:Ag and vWF:RCo were noted between groups.

From the univariable analysis, risk factors associated with thrombohemorrhagic complications were a mean 
Table 5. Primary Outcomes, Secondary Outcomes, and Subgroup Analysis of Outcomes in Essential Thrombocythemia

\begin{tabular}{|c|c|c|c|c|}
\hline & $\begin{array}{c}\mathrm{Se}(\%,) \\
(95 \% \mathrm{CI})\end{array}$ & $\begin{array}{c}\mathrm{Sp}(\%) \\
(95 \% \mathrm{CI})\end{array}$ & $\begin{array}{l}\text { PPV (\%), } \\
(95 \% \text { CI) }\end{array}$ & $\begin{array}{l}\text { NPV (\%), } \\
(95 \% \mathrm{CI})\end{array}$ \\
\hline \multicolumn{5}{|l|}{ Primary outcomes } \\
\hline \multicolumn{5}{|c|}{ Abnormal LTA for differentiation of PT from ST. } \\
\hline Epi & $\begin{array}{c}50 \\
(29.9-70.1)\end{array}$ & $\begin{array}{c}88.5 \\
(69.8-97.6)\end{array}$ & $\begin{array}{c}81.3 \\
(54.4-96)\end{array}$ & $\begin{array}{c}63.9 \\
(46.2-79.2)\end{array}$ \\
\hline Collagen & $\begin{array}{c}38.5 \\
(20.2-59.4)\end{array}$ & $\begin{array}{c}100 \\
(86.8-100)\end{array}$ & $\begin{array}{c}100 \\
(69.2-100)\end{array}$ & $\begin{array}{c}61.9 \\
(45.6-76.4)\end{array}$ \\
\hline AA & $\begin{array}{c}26.9 \\
(11.6-47.8)\end{array}$ & $\begin{array}{c}100 \\
(86.8-100)\end{array}$ & $\begin{array}{c}100 \\
(59-100)\end{array}$ & $\begin{array}{c}57.8 \\
(42.2-72.3)\end{array}$ \\
\hline Epi and either collagen or AA & $\begin{array}{c}38.5 \\
(20.2-59.4)\end{array}$ & $\begin{array}{c}100 \\
(86.8-100)\end{array}$ & $\begin{array}{c}100 \\
(69.2-100)\end{array}$ & $\begin{array}{c}61.9 \\
(45.6-76.4)\end{array}$ \\
\hline \multicolumn{5}{|l|}{ Secondary outcomes } \\
\hline \multicolumn{5}{|c|}{ Inflammatory markers for differentiation of PT from ST. } \\
\hline High ESR & $\begin{array}{c}88.5 \\
(69.8-97.6)\end{array}$ & $\begin{array}{c}65.4 \\
(44.3-82.8)\end{array}$ & $\begin{array}{c}71.9 \\
(53.3-86.3)\end{array}$ & $\begin{array}{c}85 \\
(62.1-96.8)\end{array}$ \\
\hline High CRP & $\begin{array}{c}80.8 \\
(60.6-93.4)\end{array}$ & $\begin{array}{c}61.5 \\
(40.6-79.8)\end{array}$ & $\begin{array}{c}67.7 \\
(48.6-83.3)\end{array}$ & $\begin{array}{c}76.2 \\
(52.8-91.8)\end{array}$ \\
\hline High ESR and CRP & $\begin{array}{c}69.2 \\
(48.2-85.7)\end{array}$ & $\begin{array}{c}80.8 \\
(60.6-93.4)\end{array}$ & $\begin{array}{c}78.3 \\
(56.3-92.5)\end{array}$ & $\begin{array}{c}72.4 \\
(52.8-87.3)\end{array}$ \\
\hline High ESR or CRP & $\begin{array}{c}100 \\
(86.8-100)\end{array}$ & $\begin{array}{c}46.2 \\
(26.6-66.6)\end{array}$ & $\begin{array}{c}65 \\
(48.3-79.4)\end{array}$ & $\begin{array}{c}100 \\
(73.5-100)\end{array}$ \\
\hline \multicolumn{5}{|c|}{ vWF:Ag and vWF:RCofor differentiation of PT from ST. } \\
\hline Low vWF:Ag & $\begin{array}{c}7.69 \\
(0.9-25.1)\end{array}$ & $\begin{array}{c}100 \\
(86.8-100)\end{array}$ & $\begin{array}{c}100 \\
(15.8-100)\end{array}$ & $\begin{array}{c}52 \\
(37.4-66.3)\end{array}$ \\
\hline Low vWF:RCo & $\begin{array}{c}42.3 \\
(23.4-63.1)\end{array}$ & $\begin{array}{c}88.5 \\
(69.8-97.6)\end{array}$ & $\begin{array}{c}78.6 \\
(49.2-95.3)\end{array}$ & $\begin{array}{c}60.5 \\
(43.4-76)\end{array}$ \\
\hline \multicolumn{5}{|c|}{ Abnormal LTA for the differentiation of ET from ST. } \\
\hline Epi & 50.0 & 88.5 & 62.5 & 82.1 \\
\hline Collagen & 40.0 & 100.0 & 100.0 & 81.3 \\
\hline AA & 30.0 & 100.0 & 100.0 & 78.8 \\
\hline Epi and either collagen or AA & 30.0 & 100.0 & 100.0 & 78.8 \\
\hline \multicolumn{5}{|c|}{ Inflammatory markers for the differentiation of ET from ST. } \\
\hline High ESR & 88.5 & 60.0 & 85.2 & 66.7 \\
\hline High CRP & 80.8 & 60.0 & 84.0 & 54.5 \\
\hline High ESR and CRP & 69.2 & 70.0 & 85.7 & 46.7 \\
\hline High ESR or CRP & 100.0 & 50.0 & 83.9 & 100.0 \\
\hline
\end{tabular}

PT, primary thrombocytosis; ST, secondary thrombocytosis; LTA, light transmission platelet aggregometry; Se, sensitivity; Sp, specificity; PPV, positive predictive value; NPV, negative predictive value; ADP, adenosine diphosphate; Epi, epinephrine; AA, arachidonic acid; ESR, erythrocyte sedimentation rate; CRP, C-reactive protein; vWF:Ag, von Willebrand factor antigen; vWF:RCo, ristocetin cofactor activity; ET: essential thrombocythemia.

platelet count greater than $1,837 \times 10^{9} / \mathrm{L}(\mathrm{OR} 1.01 ; 95 \%$ CI 1.002 - 1.009; $\mathrm{p}=0.006)$, Abnormal LTA using Epi (OR 0.90; 95\% CI $0.815-1.003 ; \mathrm{p}=0.057$ ), and abnormal LTA using collagen (OR 0.97; 95\% CI 0.946 - 0.998 ; $\mathrm{p}=0.034)$. However, no significant risk factors were associated with thrombohemorrhagic complications according to the multivariable analysis.

\section{Discussion}

This was a prospective study aimed at determining the role of the platelet function test as well as inflammatory markers, vWF:Ag, and vWF:RCo in distinguishing between primary and secondary thrombocytosis. The results of this study may be helpful for differentiating the diagnosis of MPN especially ET from other form of ST. Since in cases of non-mutated JAK2V617F, CALR and myeloproliferative leukemia ( $M P L)$, according to the 2016 World Health Organization diagnostic criteria, the diagnosis of ET is still based on the absence of reactive thrombocytosis (Arber et al., 2016). The diagnosis of ST is straightforward in patients who have a clinically apparent underlying disorder such as autoimmune disease, concurrent infection and active malignancy (Schafer, 2004; Rose et al., 2012). However, the diagnosis is challenging in the cases of unclear causes of thrombocytosis. In such patients, signs and symptoms may be initially helpful in the differentiation between PT and 
ST. From this study, fever was less common in cases of PT compared with ST while splenomegaly was common in PT compared with ST. Regarding the blood counts, median leukocyte and mean platelet counts were higher in PT group compared with ST group. However, there was overlap in these clinical manifestations and blood count results between patients who have PT or ST. As a result, further laboratory tests that have a good sensitivity and specificity in distinguishing between these two conditions are warranted.

From the current study, abnormal LTA induced by Epi, collagen and AA had high specificity $(88.5 \%$, $100 \%$ and $100 \%$ respectively), but low sensitivity in the differentiation between PT and ST (50\%, 38.5\% and 26.9\% respectively). These results correlated with a previous study which used the PFA-100 collagen-epinephrine (CEPI) cartridge test and epinephrine induced platelet aggregometry that showed high specificity (92\% and 96\% respectively) in the differentiation between ET and ST (Tsantes et al., 2010). In addition, this previous study also reported a high sensitivity ( $78.9 \%$ and $92 \%$ respectively) which might be explained by various methods of platelet function test, as well as differing plasma or buffers used in each study (Grignani et al., 2009). The finding that Epi had a higher sensitivity compared with collagen and AA was consistent with another study (Avram et al., 2001).

Abnormally high ESR and CRP had a high sensitivity ( $88.5 \%$ and $80.5 \%$ respectively) when it came to distinguishing between ST and PT. Moreover, the sensitivity increased up to $100 \%$ when an elevation of either ESR or CRP was used. So, a diagnosis of ST is very unlikely if both the ESR and CRP are normal. Levels of either CRP or ESR were described previously as being elevated in ST (Bashir et al., 2014; Tefferi et al., 1994). However, ESR and CRP had moderate specificity (65.4\% and $61.5 \%$ respectively) to enable differentiation of PT from ST. In some reports, it had been stated that chronic inflammation may be an important driving force for clonal evolution and disease progression in the $\mathrm{Ph}$ negative MPN (Hasselbalch et al., 2012; Geyer et al, 2015). The accuracy of using ESR and CRP as screening tool due to high sensitivity and using LTA as confirmatory test because of high specificity should be evaluated in the large further study.

From our current study, a low level of vWF:RCo was found in only $11 \%$ of patients with PT with a sensitivity of $42.3 \%$ but it had high specificity $(88.5 \%)$ when it came to the determination of PT while low vWF:Ag was not significantly present between the two groups. These results correlated with the findings reported by theInternational Society on Thrombosis and Hemostasis (ISTH) registry that functional assays of vWF either vWF:RCo or collagen binding activity ( $\mathrm{VWF}: \mathrm{CBA}$ ) appeared to be the most sensitive measurement of the vWF defect in acquired von Willebrand disease (vWD) including MPN (Federici et al., 2000). On the other hand, our current study showed that approximately $12 \%$ of patients with ST also had low vWF:RCo or had acquired vWD. This finding was in contrast to a previous report which showed that vWF:RCo was significantly higher among ST patients especially those with a platelet count of more than $700 \mathrm{x}$
$10^{9} / \mathrm{L}$ and none out of $60 \mathrm{ST}$ patients developed acquired vWD (Rottenstreich et al., 2018). However this finding was in the line with another case report concerning a hepatocellular carcinoma patient who had extreme thrombocytosis with a low vWF:RCo but high vWF:Ag resulting from antibodies that interfere with the binding of vWF to platelets without causing clearance of the vWF antigen (Chen et al., 2005).

The major limitation of this study was the small sample size since the calculated number of participants of 46 was based on the estimated percentage of abnormal LTA in PT being $80 \%$ whereas it is $30 \%$ in ST. However, the result revealed an abnormal LTA with Epi of only $50 \%$ and $12 \%$ in PT and ST cases, respectively. As a result, the 50 participants enrolled onto this study might be not adequate to detect statistical differences with a power of $95 \%$. The current study also had a limitation in the number of the patients with thrombohemorrhagic complications. However, these complications were also seen frequently in patients with PT with all cases of thrombotic complications occurring in $J A K 2 \mathrm{~V} 617 \mathrm{~F}$ mutated ET patients and all hemorrhagic complications were found in CML. This finding correlated with the incidence of major thrombosis events from a large cohort study of ET being 18\% (Carobbioet al., 2008) and the incidence of hemorrhagic complications in the chronic phase of CML was 20\% (Wehmeier et al., 1991). As a result, the identification of PT was important since it lead to the initiation of the appropriate therapy in the patients at high risk of thrombohemorrhagic complications.

Another limitation was the heterogeneity of patients in both the PT and ST groups. However, the subgroup analysis in the ET patients still revealed a high specificity of abnormal LTA by collagen (100\%) and AA (100\%) to distinguish between ET and ST as well as a high sensitivity and NPV of using either abnormal ESR and CRP (100\%) for this purpose. The subgroup analysis in CML, PV, and PMF were not analyzed. Future studies including higher numbers of patients as well as more specific groups of patients need to be performed to confirm the findings reported in this study.

In conclusion, abnormal platelet function determined by LTA with collagen, AA, epinephrine had a high specificity in enabling the differentiation between PT and ST. The use of vWF:RCo, ESR and CRP levels could well be helpful in differentiating between PT and ST. PT has a higher incidence of thrombohemorrhagic complications compared to ST but no significant risk factors associated with these complications were found.

\section{Acknowledgements}

The authors would like to thank Ms. Antika Wongthanimost sincerely for suggestions regarding the statistical analysis carried out in this study. This study was supported by the Faculty of Medicine Research Fund, Chiang Mai University, Thailand (112-2560).

\section{References}

Arber DA, Orazi A, Hasserjian R, et al (2016). The 2016 revision 
to the WHO classification of myeloid neoplasms and acute leukemia. Blood, 127, 2391-405.

Avram S, Lupu A, Angelescu S, Olteanu N, Mut-Popescu D (2001). Abnormalities of platelet aggregation in chronic myeloproliferative disorders. J Cell Mol Med, 5, 79-87.

Barbui T, Finazzi G, Falanga A (2013). Myeloproliferative neoplasms and thrombosis. Blood, 122, 176-84.

Bashir AB, AgeepAK, Abufatima AS, Mohamedani AA (2014). Reactive thrombocytosis and erythrocyte sedimentation rate in patients with pulmonary tuberculosis. $J$ Med Lab Diagn, 5, 29-34.

Beer PA, Erber WN, Campbell PJ, Green AR (2011). How I treat essential thrombocythemia. Blood, 117, 1472-82.

Bleeker JS, Hogan WJ (2011). Thrombocytosis: diagnostic evaluation, thrombotic risk stratification, and risk-based management strategies. Thrombosis, 2011, 536062.

Carobbio A, Finazzi G, Antonioli E, et al (2008). Thrombocytosis and leukocytosis interaction in vascular complications of essential thrombocythemia. Blood, 112, 3135-7.

Carobbio A, Thiele J, Passamonti F, et al (2011). Risk factors for arterial and venous thrombosis in WHO-defined essential thrombocythemia: an international study of 891 patients. Blood, 117, 5857-9.

Chen CC, Chang JY, Liu KJ, et al (2005).Hepatocellular carcinoma associated with acquired von Willebrand disease and extreme thrombocytosis. Ann Oncol, 16, 988-9.

Rottenstreich A, Shai E, Kleinstern G, et al (2018). Assessment of procoagulant potential in patients with reactive thrombocytosis and its association with platelet count. Eur J Haematol, 100, 286-93.

Federici AB, Rand JH, Bucciarelli P, et al (2000). Acquired von Willebrand syndrome: data from an international registry. Thromb Haemost, 84, 345-9.

Geyer HL, Dueck AC, Scherber RM, Mesa RA (2015).Impact of inflammation on myeloproliferative neoplasm symptom development. Mediators Inflamm, 2015, 284706.

Grignani C, Noris P, Tinelli C, Barosi G, Balduini CL (2009). In vitro platelet aggregation defects in patients with myeloproliferative disorders and high platelet counts: Are they laboratory artefacts?. Platelets, 20, 131-4.

Harrison P (2005). Platelet function analysis. Blood Rev, 19, 111-23.

Hasselbalch HC (2012). Perspectives on chronic inflammation in essential thrombocythemia, polycythemia vera, and myelofibrosis: is chronic inflammation a trigger and driver of clonal evolution and development of accelerated atherosclerosis and second cancer?. Blood, 119, 3219-25.

Kumar S, Pruthi RK, Nichols WL (2002). Acquired von Willebrand Disease. Mayo Clin Proc, 77, 181-7.

Rodgers GM, Means RT (2014). Thrombocytosis and essential thrombocythemia.In: 'Wintrobe's Clinical Hematology'Eds Greer GP, Arber DA, Glader B, et al, eds. Lippincott Williams and Wilkins, Philadelphia, USA, pp 1122-7.

Rose SR, Petersen NJ, Gardnerd TJ, Hamill RJ, Trautner BW (2012). Etiology of thrombocytosis in a general medicine population: analysis of 801 cases with emphasis on infectious causes. J Clin Med Res, 4, 415-23.

Schafer AI (2001). Thrombocytosis and thrombocythemia. Blood Rev, 15, 159-66.

Schafer AI (2004). Thrombocytosis. NEngl J Med, 350, 1211-9.

Tefferi A, Ho TC, Ahmann GJ, Katzmann JA, Greipp RR (1994). Plasma interleukin-6 and C-reactive protein levels in reactive versus clonal thrombocytosis. Am J Med, 97, 374-8.

Tiede A, Rand JH, Budde U, Ganser A, federici AB (2011). How I treat the acquired von Willebrand syndrome. Blood, 117, 6777-85.

Tsantes AE, Dimoula A, Bonovas S, et al(2010). The role of the platelet function analyzer (PFA)-100 and platelet aggregometry in the differentiation of essential thrombocythemia from reactive thrombocytosis.Thromb Res, 125, 142-6.

Wehmeier A, Daum I, Jamin H, Schneider W (1991). Incidence and clinical risk factors for bleeding and thrombotic complications in myeloproliferative disorders: A retrospective analysis of 260 patients. Ann Hematol, 63, $101-6$.

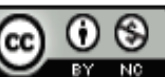

This work is licensed under a Creative Commons AttributionNon Commercial 4.0 International License. 